\title{
Cerebral Tissue Response to Electrode Implantation
}

\author{
RONALD F. DODSON, L. W-F CHU, N. ISHIHARA
}

SUMMARY: Tissue response to platinum electrodes was assessed after an eight-day implantation period. The regions of study included the cortical areas at the opercular gyri and at the sulcus parieto-occipitalis externus, as well as the sub-cortical white matter in these areas.

Perivascular and intraparenchymal hemorrhagic lesions as well as edematous changes characterized both by extensive intra and extracellular swelling were noted. Numerous phagocitic elements and

RESUME: Nous avons étudié la réponse du tissu après l'implantation pendant 8 jours d'électrodes de platine. Les régions étudiées incluaient les aires corticales de la circonvolution operculaire el du sillon pariéto-occipital externe, ainsi que la substance blanche sous-corticale de ces mêmes zones.

Nous avons noté des lésions hémorragiques périvasculaires et intraparenchymateuses, ainsi que des changements oedémateux caractérisés par de loedème

From the Department of Experimental Pathology. The University of Texas Health Center at Tyler, Texas 75710. The Baylor-Methodist Center for Cerebrovascular Research and The Department of Pathology. Baylor College of Medicine. Houston. Texas 77030 .

Reprint requests to: Ronald F. Dodson, Ph.D. Chicf: Departments of Experimental Pathology \& Environmental Sciences, University of Texas Health Center. P.O. Box 2003, Tyler, Texas 757I0. U.S.A.

This work was supported in part by Grant NS 09287 from the National Institute of Neurological and Communicative Disorders and Stroke, Bethesda, Maryland 200/4. degenerative structures were present at the electrode/parenchimal interface.

Tissue alterations were asymmetrical as observed both around and at the tip of the implanted electrode. The parenchymal alterations extended from $0.2 \mathrm{~mm}$ to $3.5 \mathrm{~mm}$ distance from the electrode path/ parenchymal interface.

Greater tissue involvement was found in the subcortical white matter as compared to the adjacent cortical gray matter.

intense intra et extracellulaire. II y avait de nombreux éléments phagocylaires et des structures dégénératives à l'interphase électrode/parenchime.

Ces altérations tissulaires étaiem asymétriques autour et au bout de l'électrode implantée et s'étendaient sur une distance de 0.2 a $3.5 \mathrm{~mm}$ de l'interphase tracé de l'électrode /parenchyme.

Nous avons trouve' plus d'atleinte dans la substance blanche sous-corticale que dans la matière grise adjacente.

\section{INTRODUCTION}

Although much data concerning function of the brain has been obtained by using electrode implantation techniques, limited information exists concerning cerebral tissue response in the implanted area.

Recently electrode implantation alone has been shown to influence certain functional and behavioral patterns (Boast et al., 1976; Herzet al., 1974; Persson \& Hansson, 1976; Robinson et al., 1975; Wetzel et al., 1969). Boast et al., (1976) have suggested that these changes might be related to hemodynamic alterations due to the hemorrhagic and traumatic influence of the implantation method.

Morphological studies of electrode track/brain parenchymal interactions by Collias and Manuelidis (1957) reported tissue reaction at the light microscopy level. Schultz and Willey
(1976) reported ultrastructural changes following chronically implanted electrodes. After an interval of thirty days, the latter workers reported parenchymal response consisting of numerous giant cells and phagocytes as well as changes in neuronal and astrocytic components. Schultz and Willey (1976) further reported an increase in the number of blood vessels in the sheath zone as well as an expanded extracellular space.

The present work defines the ultrastructural tissue response in baboons in which electrode implantation had been maintained for an eight-day period. These data will provide insight into those tissue changes which occur in acute/ subacute animal models.

\section{MATERIALS AND METHODS}

The hydrogen and oxygen electrodes used in the study were modified (Meyer et al., 1972) from the technique of Aukland, Bower and Berlinen (1964). These consisted of fine platinum wire insulated with siliconephenolic resin (Gage coat ${ }^{\mathrm{K}} \# 4$ ). The tip diameter was approximately $150-250 \mu$ and extended as an uninsulated region of $1-2 \mathrm{~mm}$ in length. A potential of +0.65 volt was applied to the hydrogen electrode and -0.65 volt to the oxygen electrode, and a $10^{6}$ resistor was attached in series with the circuit. The output current generated from both hydrogen and oxygen electrode was amplified with microvolt meters and recorded by means of a four-channel linear deflection pen recorder.

Four young adult baboons (papio enubis) weighing $5-12 \mathrm{~kg}$ were anesthetized with intravenous pentobarbital in doses of $25 \mathrm{mg} / \mathrm{kg}$ body weight. Following tracheostomy, the animals were immobilized with $10 \mathrm{mg}$ of gallamine triethiodide (Flaxedil $^{\mathrm{R}}$ ) and respiration was maintained 
constantly with a Harvard variable speed respirator to maintain $\mathrm{PaCO}_{2}$ between $38-43 \mathrm{mmHg}$. Arterial $\mathrm{PO}_{2}$ and $\mathrm{PCO}_{2}$ were monitored digitally by a mass spectrometer through a catheter tip inserted into the thoracic aorta via the femoral artery. Body temperature was controlled at 36$38^{\circ} \mathrm{C}$ by a heating mat. Systemic arterial blood pressure was monitored with a Statham transducer by means of a catheter inserted into the left internal carotid artery via the lingual artery to permit injection of a bolus of $1.5 \mathrm{ml}$ saline saturated with hydrogen gas.

After preparations of the animals for physiological monitoring were completed, the oxygen and hydrogen electrode pairs were sterotaxically implanted into four regions in both hemispheres and secured to the skull by dental methyl methacrylate. These four implanted regions were: (1) cortex of the opercular gyri; (2) subcortical white matter of the same region; (3) cortex of the sulcus parietooccipitalis externus, and (4) subcortical white matter from the same area.

Eight days after implantation, the animals were sacrificed under anesthesia for ultrastructural studies by whole body perfusion with a $3 \%$ glutaraldehyde in $0.1 \mathrm{M}$ phosphate buffer. The brain and calvarium were immersed in the same fixative for an additional 12 hours for further hardening of tissue and minimal tissue disturbance. The calvarium and meninges were carefully removed, leaving the electrode tracks readily visible in the firm glutaraldehyde fixed tissue. Tissue blocks were cut across the entire electrode path at levels which included areas of tip, close to tip, mid-track, and brain surface areas. The samples were placed in the glutaraldehyde fixative for an additional 12 hours, washed in two phosphate buffer rinses and post-fixed in $1 \%$ osmium tetroxide buffered solution. Standard ethanol dehydration was followed by Spurr (1969) embedment.

Semithin plastic sections $(0.5-1 \mu$ thick) were cut across the entire electrode track and surrounding tissue. These sections were stained with toluidine blue and viewed by light microscopy for determination of optimal fixation, specimen orientation, and selection of areas for thin sectioning.

Thin sections were prepared on a LKB Microtome III, stained with uranyl acetate and lead citrate (Reynolds, 1963) and reviewed with an RCA EMU-4 electron microscope.

\section{RESULTS}

At the light microscopy level, erythrocytic clumps were present at the electrode track/parenchymal interface, around capillaries, and at scattered loci within the adjacent parenchyma (Fig. 1a). Localized swelling and/or necrosis were also evident in involved area (Fig. la). This same hemorrhagic and edematous tissue response was found in the electrode tip region (Fig. 1b).

When measurements of the extent of tissue involvement were made from semithin sections, it was found that changes were detectable from the electrode track/parenchymal interface at a distance of a minimum of $0.2 \mathrm{~mm}$ to a maximum of $3.5 \mathrm{~mm}$. Furthermore, these changes did not follow a

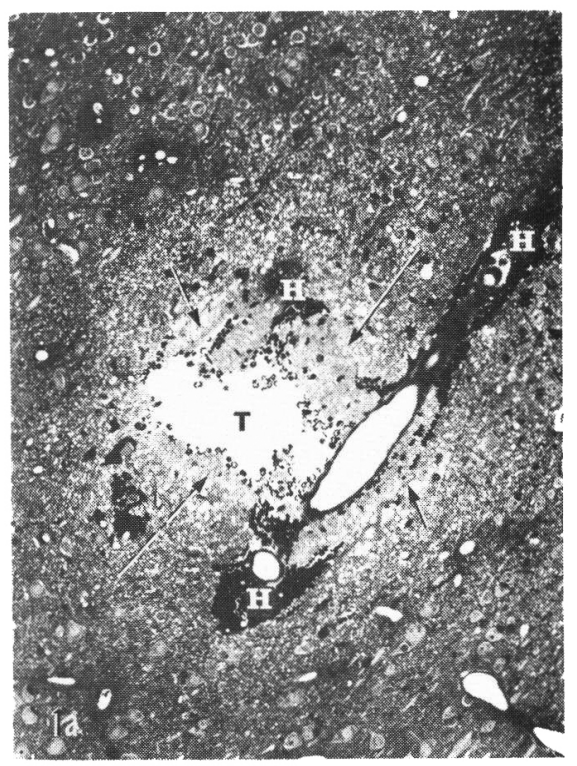

Figure $1 A-$ The extent of tissue response is shown in this light microscopy section of the electrode track (T). Hemorrhagic $(\mathrm{H})$ and edematous influences (arrows) are evident in the surrounding parenchyma, semithin section (x300). symmetrical pattern of spread from the central path and were more marked in subcortical white matter than in gray matter.

Ultrastructurally, the hemorrhagic aggregates were comprised of an erythrocytic mass containing scattered leukocytes (Fig. 2). No morphological correlation could be drawn between intraparenchymal clumps and an extravasation of cells involving the microvasculat ure, since capillary complexes within the same area were intact (Fig. 2). Both intracellular and extracellular swelling was present in the more necrotic regions.

The border formed at the electrode/ parenchymal interface was composed of necrotic parenchymal elements within a fibrous matrix which consisted mainly of collagen fibers (Fig. 3). Numerous osmiophilic structures and myelin swirls indicated the phagocytic/catabolic influences within the area (Fig. 3).

Progressively fewer abnormalities were found in samples taken farther from the electrode/parenchymal interface. In the outermost areas of parenchyma in which changes were detectable, these changes were limited

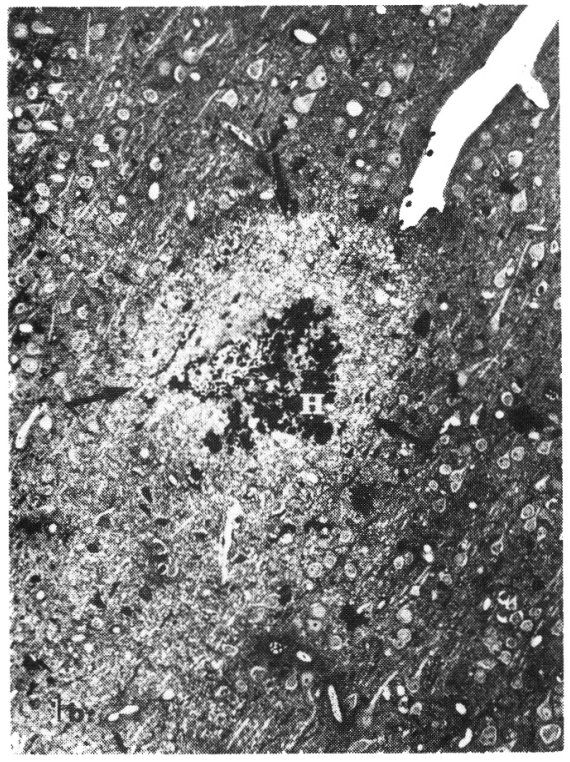

Figure $I B$ - The parenchyma in the subtip area contains a centralized hemorrhagic zone $(\mathrm{H})$ within a clearly defined edematous area (arrows), semithin section $(\mathrm{x} 300)$. 
to perivascular edema consisting of astrocytic swelling (Fig. 4). The other parenchymal components in such a region of minimal involvement were normal in appearance.

More advanced tissue involvement was found in subcortical white matter than in the adjacent cortical gray matter. Such an area contained both intra and extracellular response which resulted in capillary crenation. abundant phagocytic activity, distorted myelin sheath and axons as well as degenerative mitochondria and excessive extracellular space (Fig. 5).

\section{DISCUSSION}

Our ultrastructural observations confirmed tissue response eight days after electrode implantation. A border zone at the electrode/parenchymal interface was composed of a mixture of hemorrhagic, fibrous, phagocytic, and necrotic elements. A clearly defined sheath of a cellular lining as was reported in a study following 30 days chronic implantation (Schultz and Willey, 1976) had not developed in these animals. In the present studies no detectable capillary proliferation was encountered in border zone. The endothelial wall of the capillaries in involved regions was continuous even though edematous changes were evident in some pericytic and endothelial cytoplasm.

Extensive necrosis was observed at the electrode interface with the parenchyma and was evidenced by numerous phagocytes, reduced cellularity and increased number of osmiophilic structures within the astrocytes, oligodendroglia, and neurons.

The deeper parenchymal response emphasized that the susceptibility of astrocytic elements in that involvement was limited to perivascular swelling within astrocytic foot processes. This tissue reaction was similar to that observed in acute response to cerebral ischemia (Dodson et al, 1975).

No unusual glycogen response was noted in the reactive \%one, as has been reported following cerebral stab wound (Farkas-Bargeton et al, 1972).
From our observations as well as those of others (Collias \& Manuelidis, 1957. Schult7. \& Willey, 1976), it is evident that implantation of electrodes elicits a tissue response which is definable, reproducibly limited as to involvement, and divided into developmental stages. Although the degree of involvement between traumatic, hemodynamic, and cytotoxic factors remains unclarified, the net effect is definable in tissue response and should not be ignored in conclusions drawn from studies involving implantation.

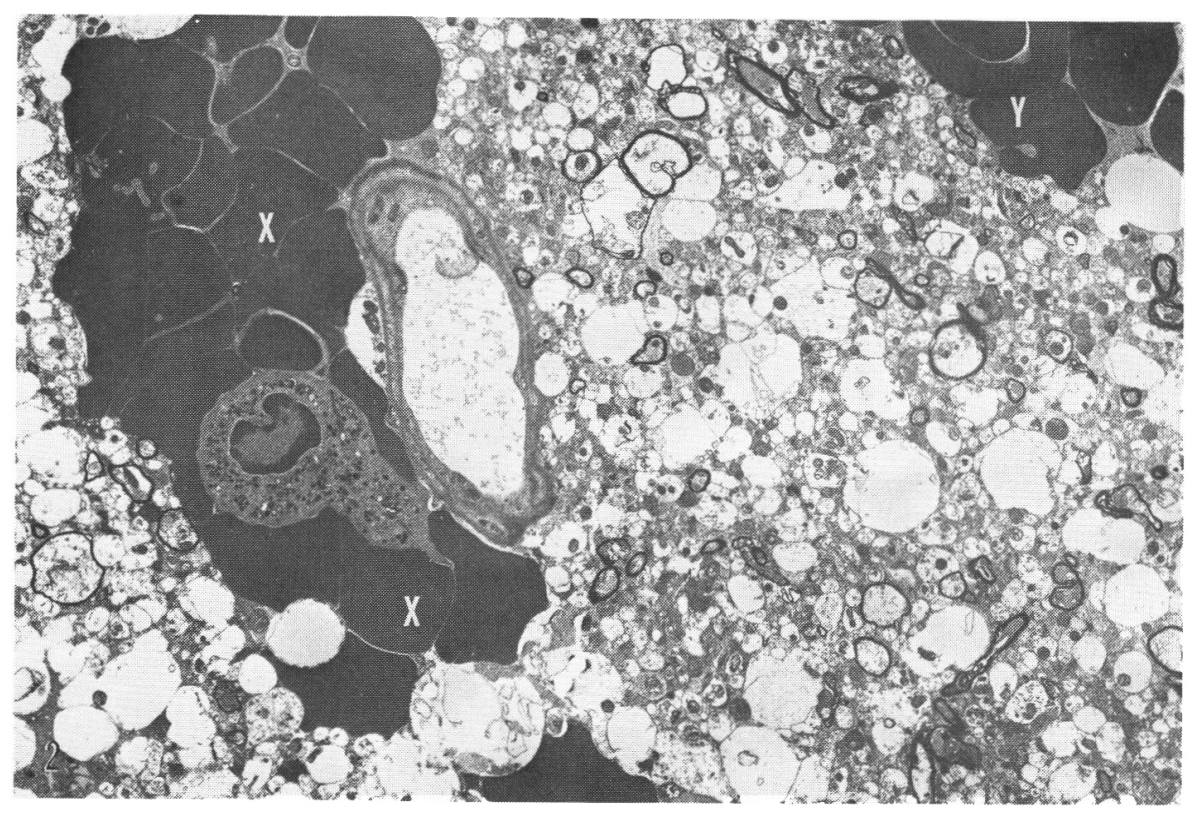

Figure 2 - A typical example of parenchymal response in ward from the track parenchymal interface consists of perivascular $(X)$ and intraparenchymal $(Y)$ hemorrhagic clumps as well as extensive intra and extracellular edema (x4000).

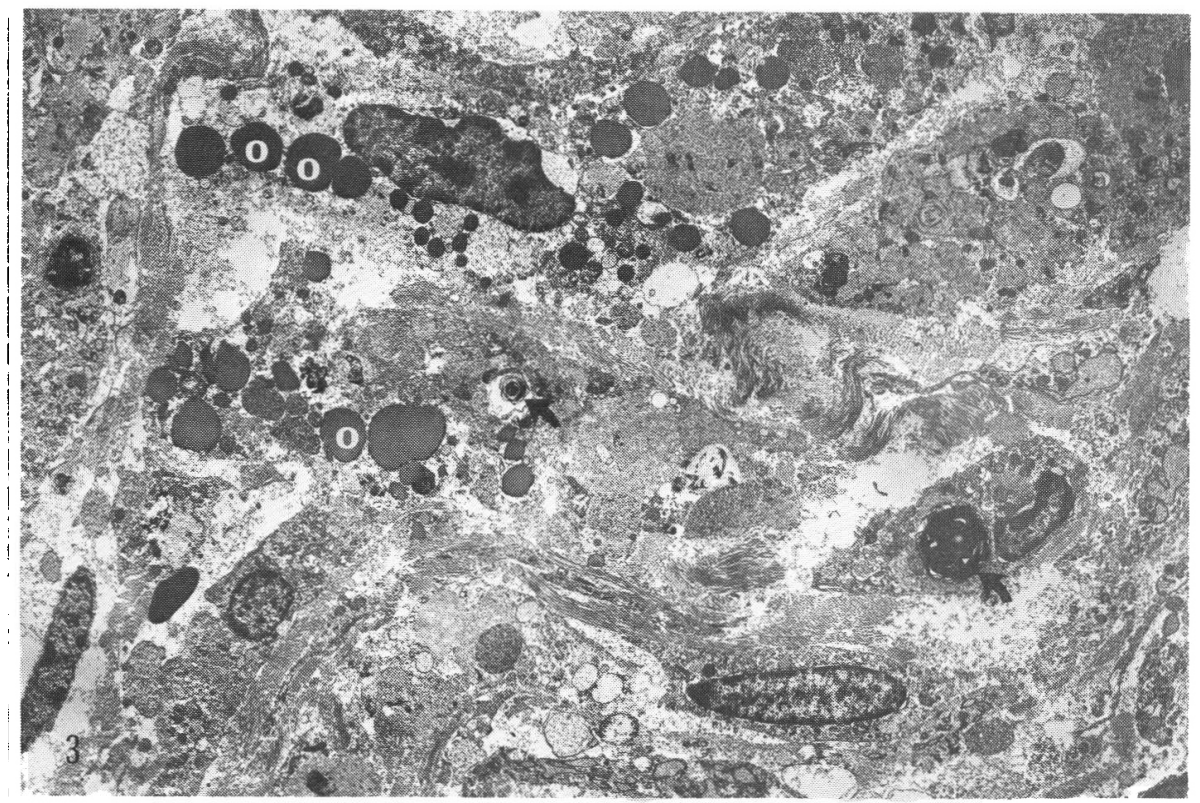

Figure 3-The track/parenchymal interface zone shows a more degenerative stage of involvement with numerous osmiophilic bodies $(\mathrm{O})$ and membranous swirls (arrows) being present in a fibrous matrix $(\times 3,800)$. 


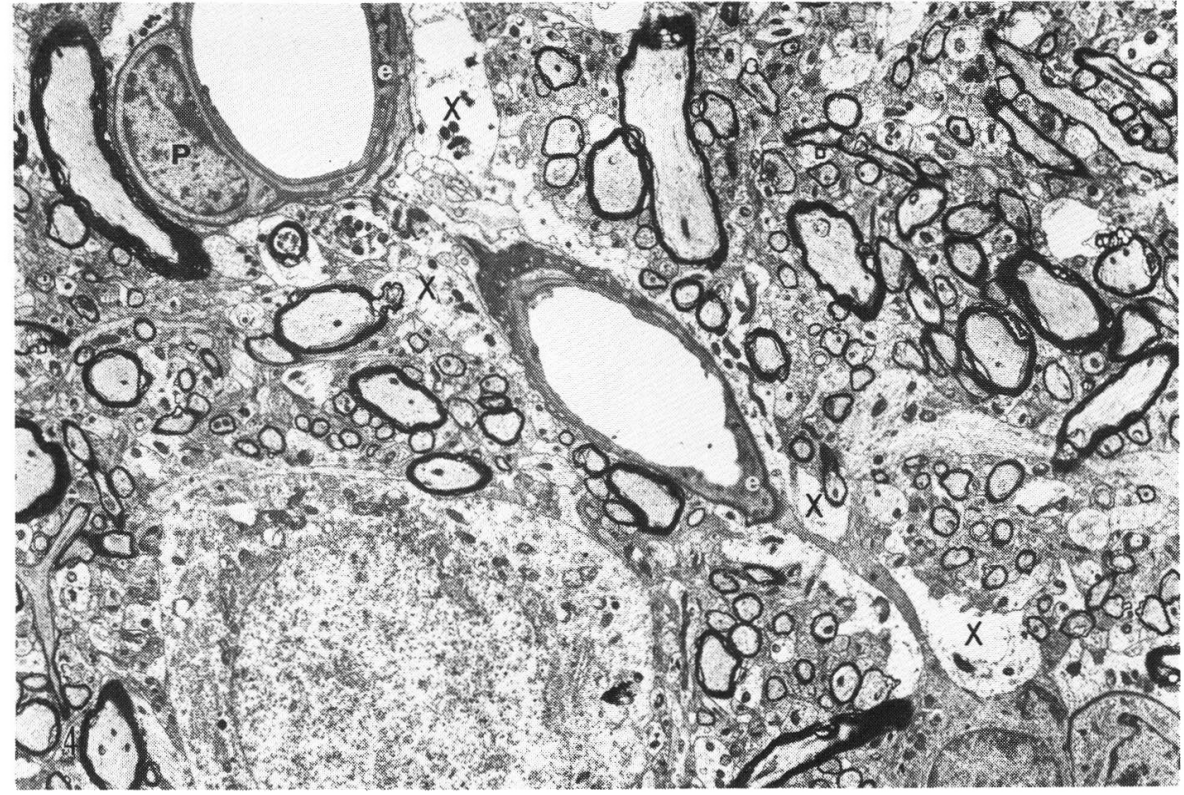

Figure 4 -- This field represents an area of deeper parenchymal response which contains only perivascular, intra-astrocytic swelling (X). Capillary integrity, i.e. endothelial cells (e) as well as pericytes $(P)$, is intact $(\times 4,500)$.

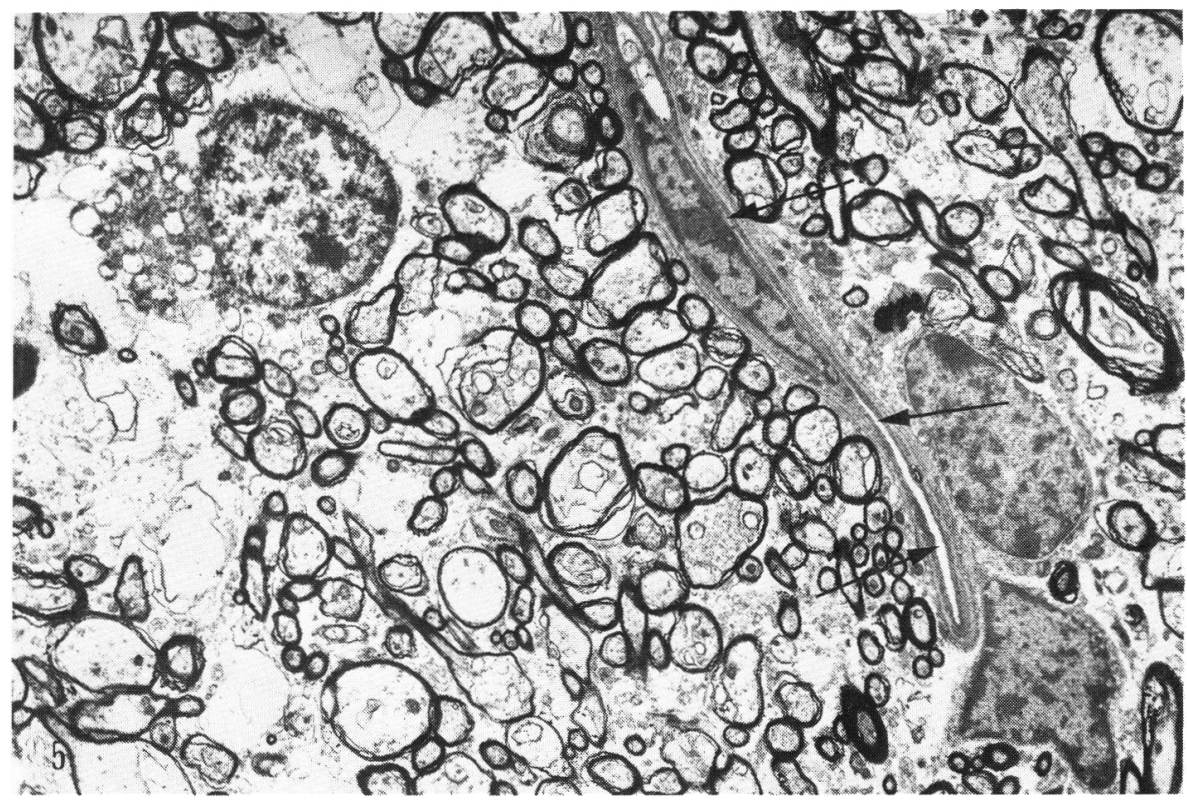

Figure 5 - Intraparenchymal changes adjacent to the electrode track in white matter show much more advanced intra and extracellular swelling as well as microvascular crenation and the resultant luminal narrowing (arrow) $(\times 5,000)$.

\section{REFERENCES}

AUKLAND, K., BOWER, B. F., and BERLINEN, B. W. (1964). Measurement of local blood flow with hydrogen gas. Circ. Res., 14:164-187.

BOAST, C. A., REID, S. A., JOHNSON, P. and ZORNETZER, S. F. (1976). A caution to brain scientists: Unsuspected hemorrhagic vascular damage resulting from mere electrode implantation. Brain Research. 103:527-534.

COLLIAS, J. C., and MANUELIDIS, E. E (1957). Histopathological changes produced by implanted electrodes in cat brains. J. Neurosurg., 14:302-328.

DODSON, R. F., TAGASHIRA, Y., KAWAMURA, Y., AND CHU, L. W-F (1975). Morphological responses of cerebral tissues to temporary ischemia. Can. J. Neurol. Sci. 2:173-177.

FARKAS-BARGETON, E., OLSSON, Y., GUTH, L., and KLATZO, I. (1972). Glycogen reaction to cerebral stab wound during maturation of rat brain. Acta Neuropath. (Berl.), 22:158-169.

HERZ, M. J., MARSHALL, K. E., and PEEKE, H. V. S. (1974). Brain stimulation and behavior: Controls and consequences. Physiol. Psychol., 2:184-186.

MEYER, J. S., FUKUUCHI, Y., KANDA, T., SHIMAZU, K., and HASHI, K. (1972). Regional cerebral blood flow measured by intracarotid injection of hydrogen. Comparison of regional vasimotor capacitance from cerebral infarction versus compression. Neurology, 22:571-584.

PERSSON, L., and HANSSON, H. A. (1976). Reversible blood-brain barrier dysfunction to peroxidase after a small stab wound in the rat cerebral cortex. Acta Neuropath (Berl.), 35:333-342

REYNOLDS, E. S. (1963). The use of lead citrate at high $\mathrm{pH}$ as an electron opaque stain in electron microscopy. J. Cell Biol.. 17:209213

ROBINSON, N., DUNCAN, P., GEHRT, M. SANCES, A., and EVANS. S. (1975). Histochemistry of trauma after electrode implantation and stimulation in the hippocampus. Arch. Neurol., 32:98-102.

SCHULTZ, R. L., and WILLEY, T. J. (1976). The ultrastructure of the sheath around chronically implanted electrodes in brain. J. Neurocytol., 5:621-642.

SPURR, A. R. (1969). A low-viscosity epoxy resin embedding medium for electron microscopy. J. Ultrastruct. Res., 26:31-43.

WETZEL, M. C., HOWELL, L. G., and BEARIE, K. G. (1969). Experimental performance of steel and platinum electrodes with chronic monophasic stimulation of the brain. J. Neurosurg., 31:658-669. 